\title{
Composite Material Stent Comprising Metallic and Non-metallic Materials
}

\author{
Yuzo Shomura, MD. \\ Senri Chuo Hospital, Department of Surgery \\ Japan
}

\section{Introduction}

Stents that are used for the purpose of canceling stenotic lesions in luminal organs are classified into three types according to the materials used. The first type is ones comprising silicone, and the second type metal. A composite of silicone and metal is employed in the third type. Recent years have seen an increase in the number and range of products of the last type. I am one of those who hold that this is because a stent consisting of a composite material complements those consisting of single materials. The advantage of the silicone stent is the easy removal from the body. The disadvantages include its weak expansile force, requirement for general anesthesia when implanting it in the body, and unstableness. In contrast, the metallic stent is easily inserted in the body and offers strong expansile force while it is difficult to remove once it is inserted. For another disadvantage, it may cause damage to peripheral tissues by superdistention. In order to complement these disadvantages of stents made of single materials, stents comprising a composite of these materials are currently being developed.

I as well as other researchers list the following conditions for an ideal stent.

First, as for the mechanical properties as a structure for canceling stenotic lesions, a stent must:

1. have sufficient expansile force to cancel stenotic lesions,

2. minimize the stress on normal tissues by adjusting its shape according to organs, and

3. not damage the physiologic functions of organs such as secretion and peristalsis.

Second, as a measure against temporal and/or spacial changes of a lesion, a stent must:

1. be removed and reinserted easily when necessary, and

2. retain its properties for an extended period of time.

Third, as for additional properties as a treatment device, a stent must:

1. be able to contain and release therapeutic medicine.

There is a long way to go before a stent is developed that fulfills all these conditions. For the time being, it is more realistic to select one which better meets the specific requirement of each case. We devised a method of knitting metallic and non-metallic materials with a view to modifying the structural properties of the knitted metallic stent. This method enables modification of stent properties in accordance with a specific lesion by changing the nonmetallic material to be used with the metal wire. For instance, for improved stent removability, adopting a stent structure with a mesh of bio-absorbing material knit together with metallic wire makes a stent easy to remove. After the bio-absorbing material dissolves, 
the metallic component remains as a simple spiral, which can be straightened and removed easily by pulling it at one end. Also, compared with metallic materials coated with therapeutic medicine, non-metallic materials such as bio-absorbing textile can contain medicine more easily so it can be designed to optimize the release of the medicine. In addition, as mentioned above, the metallic part can be removed easily after the medicine is released.

The mechanical properties of a composite material stent of metallic and non-metallic materials can be adjusted as well. Metallic stents are composed of metals such as nickel titanium (Ni-Ti) and stainless steel, and the physical properties are defined by the design of the mesh and by the material properties of the metals used. Stents with strong expansile force generally show high elasticity against bending. For this reason, if an indwelling stent with strong expansile force is inserted in a curved luminal organ, the restoring force caused by bending yields excess surface pressure to tissues, which may result in ulceration of and perforation in the tissues. (Fransen et al. 2003) Also, when a stent is bent to an acute angle, adjacent struts come into contact and transform themselves in such a way that they protrude inward, which may result in kinks. (Mori et al. 2004) In a composite material stent of metallic and non-metallic materials, mechanical properties such as expansile force and restoring force are determined almost exclusively by the material and structural properties of the metallic component, as the materials have significantly different degrees of bending stiffness. That is, the structural properties of a hybrid stent are similar to those of metallic spirals. Therefore, a composite material knitted stent realizes both strong expansile force and applicability to curved luminalis.

For this experiment, two types of composite material knitted stents were developed: one using stainless wire and PLA fiber, and the other using $\mathrm{Ni}$ - $\mathrm{Ti}$ wire and poly-phenylenebenzobisoxazole (PBO) fiber. The former was developed to evaluate the removability after the dissolution of the PLA fiber. The latter was used to evaluate mechanical properties such as the radial expansile force, restoring force against bending, and resistance against kinks.

\section{Composite material stent comprising metallic wire and bioabsorbable fiber: mechanical characteristics and retrievability}

\subsection{Background}

Metallic knitted stents are characterized by strong radial force, thin wall structure, and simple stenting procedure under local anesthesia. The major disadvantage of these stents, however, is the difficulty in removal from the body (Noppen et al., 2005). Once placed in a luminal organ, it is often difficult to fold and withdraw the expanded stent. Song et al. reported a metallic stent retrieval procedure using a hook, which allows easy stent removal by pulling the hook after attachment to the stent body (Song et al., 1999). The retrieval hook is useful for certain types of metallic stent structure, but may not be applied to all types of stent textile pattern as some cannot be folded up sufficiently by pulling the end of wire outwards.

One of the reasons why conventional knitted metallic stents are difficult to remove from the body is that they are made with a wire knitted in a cross-linked textile pattern. When stent removal is necessary, it is often difficult to fold up the complex cross-linked wire structure. The only way to remove the stent is to remove it as a whole structure.

We examined the textile patterns of present metallic stents to develop a simple unlocking procedure, and found that cross-linking of the metallic wire can be avoided if the textile is 
knitted from two different wires, one of which comprising a non-metallic material. This concept can be applied to a composite material stent comprising a metallic wire and a bioabsorbable fiber.

In this study, we made a composite material stent comprising a metallic wire and a Poly Lactic Acid (PLA) fiber (hybrid stent). With such a stent, metallic wire is cross-linked only with bioabsorbable fiber, not with itself, and it can easily be deformed and removed after bioabsorbable fiber has degraded.

The purpose of this study is to evaluate mechanical characteristics of the composite material stent and to examine its retrievability after bioabsorbable fiber degradation.

\subsection{Material and methods}

\subsubsection{Stent structure}

The composite material stent was produced from stainless steel wire and poly lactic acid (PLA) fiber. They were cross knitted in the same textile pattern of an commercial Ultra Flex stent (Fig. 1). American National Standard of Industry (ANSI) 304 grade stainless steel wire of $0.2 \mathrm{~mm}$ in diameter was knitted with a $0.23 \mathrm{~mm}$ PLA monofilament fiber (520T; Chukoh Chemical Industries, Ltd. Fukuoka, Japan: S-P stent). Stent size is $20 \mathrm{~mm}$ in diameter and 60 $\mathrm{mm}$ in length.

For comparison of mechanical strength, identical test stent of the PLA monofilament fiber only was made (P-P stent).

Commercial metallic stents, Ultra Flex (Boston Scientific Co., Natick, USA) of the same size were also prepared for comparison.

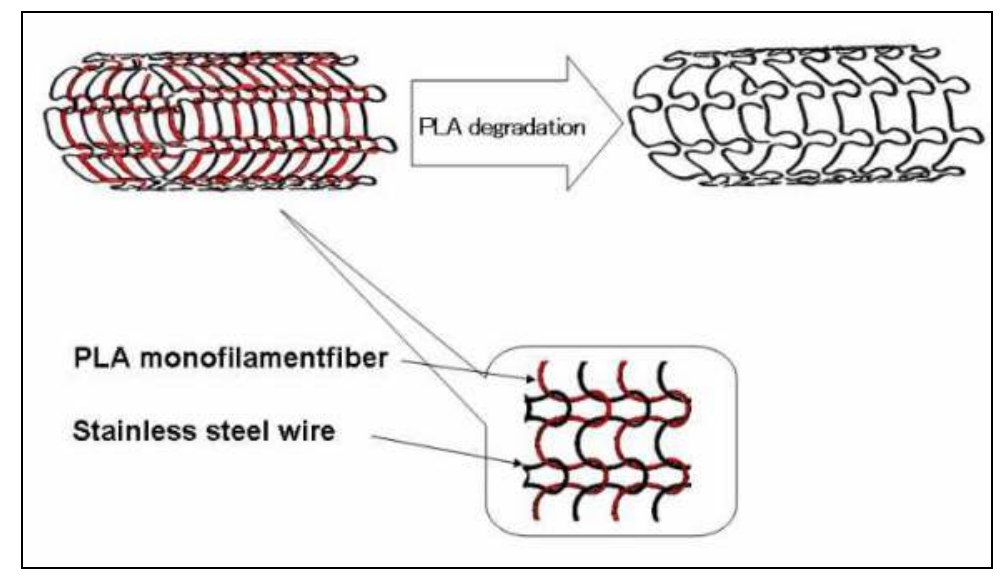

Fig. 1. Schematic structure of composite material stent; A stainless steel wire and a PLA monofilament fiber were knitted in the same textile structure as Ultra Flex stent. Non-crosslinked metallic wire can be straightened after PLA fiber degradation, and easily removed from the body

\subsubsection{Evaluation of mechanical properties}

1. Radial expansile force

The radial expansile forces of the test stents were measured as the resilient force response against circumferential shrinkage stress load, as described previously (Miura et al., 2003). In 
summary, a test stent covered with a non-stretchable film was placed on a board fixed to one end of the covering film. The other end of the film was connected to a push-pull gauge (Imada Co.,Toyohashi, Japan), and shrinkage load was added to the stent by pulling the film. The load added to the stent was recorded for stent diameter change (Fig. 2 (a)).

2. Lateral stent rigidity

Mechanical strength against lateral compression, defined as stent rigidity in this study, was measured as the resilient force response to lateral compression load. The test stent was set in a load cell, and lateral compression stress was added to the point when stent diameter reduced to $50 \%$ of the original dimension. The resilient force at this point was recorded (Fig. $2(b))$.

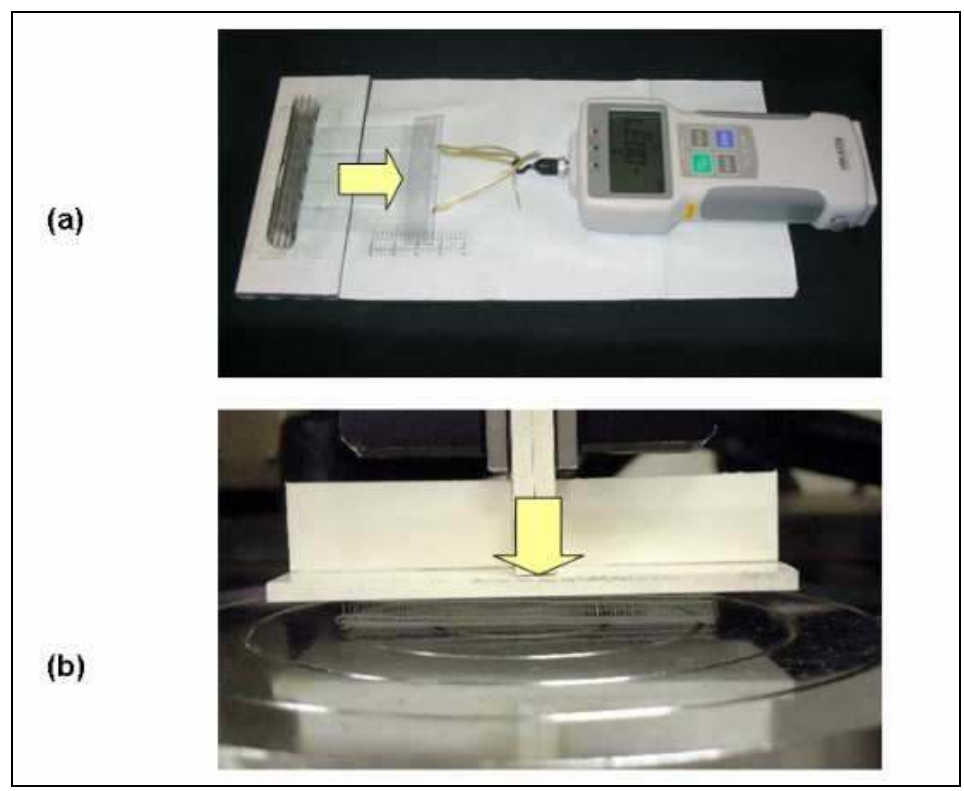

Fig. 2. Evaluation of mechanical properties; (a) Radial expansile force was evaluated as the resilient force response against circumferential shrinkage stress load applied to the test stent. (b) Resilient force against lateral compression load was measured at $50 \%$ reduction of the original diameter

3. Change in radial expansile force after PLA fiber degradation

To estimate change of mechanical strength after PLA fiber degradation, an artificial PLA degradation process was added to S-P stent by immersing it into a water bath at $80^{\circ} \mathrm{C}$ for 48 hours. The change in radial expansile force was compared to the original values P-P stent was also tested in the same way for comparison.

\subsection{Retrievability of metallic core component}

$\mathrm{S}-\mathrm{P}$ stent underwent the heating process mentioned above was set in a silicone tube. One end of the metallic core component was grasped using forceps and pulled outwards to unlock spiral structure. Torsion of the metallic wire, stent displacement, resistance in the unlocking process and deformities in the core were visually evaluated. 


\subsection{Results}

\subsubsection{Mechanical properties}

1. Radial expansile force

S-P stent exhibited linear radial force response up to the point when the diameter was $85 \%$ of the original dimension. This linearity was comparable to that of the same size UltraFlex stent. The lumen of P-P stent was obstructed at 15 percent diameter shortening, and did not exhibit radial force increase over this point (Fig. 3).

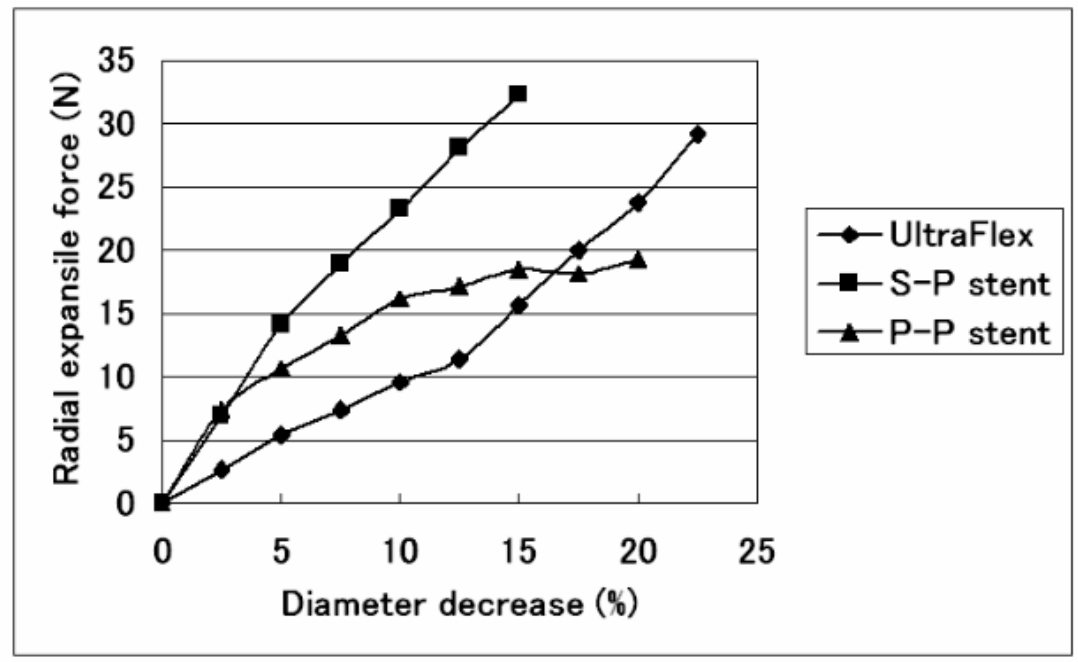

Fig. 3. Radial expansile force response against circumferential shrinkage stress load; The S-P stent presented linear radial force increase within the range of 15 percent shortening of the original diameter. In P-P stent, linear response was lost when the diameter decreased by $15 \%$

\section{Stent rigidity}

Resilient force of a S-P stent against lateral compression was $86.8 \mathrm{kN}$ and $21.1 \mathrm{kN}$ for S-P stent at the point when stent diameter reduced to $50 \%$ of the original dimension. It was approximately four times than that of the same structural S-S stent. (Table 1).

\begin{tabular}{|l|l|}
\hline Stent & Resilient force $(\mathrm{kN})$ \\
\hline S-P stent & 86.8 \\
\hline P-P stent & 21.1 \\
\hline
\end{tabular}

Table 1. Resilient force of test stents against lateral compression at the point when stent diameter reduced to $50 \%$ of the original dimension

3. Change in radial expansile force after PLA fiber degradation

S-P stent undergoing the heat process showed a slight decrease in radial expansile force, but it was not more than $5 \%$ within the range of a $15 \%$ reduction in original stent diameter. In contrast, P-P stent did not exhibit an effective radial force, and was destroyed at $12 \%$ diameter reduction (Fig. 4). S-P stent maintained its original shape even after PLA degradation. In contrast, P-P stent was easily crushed by slight compression loads (Fig. 5). 


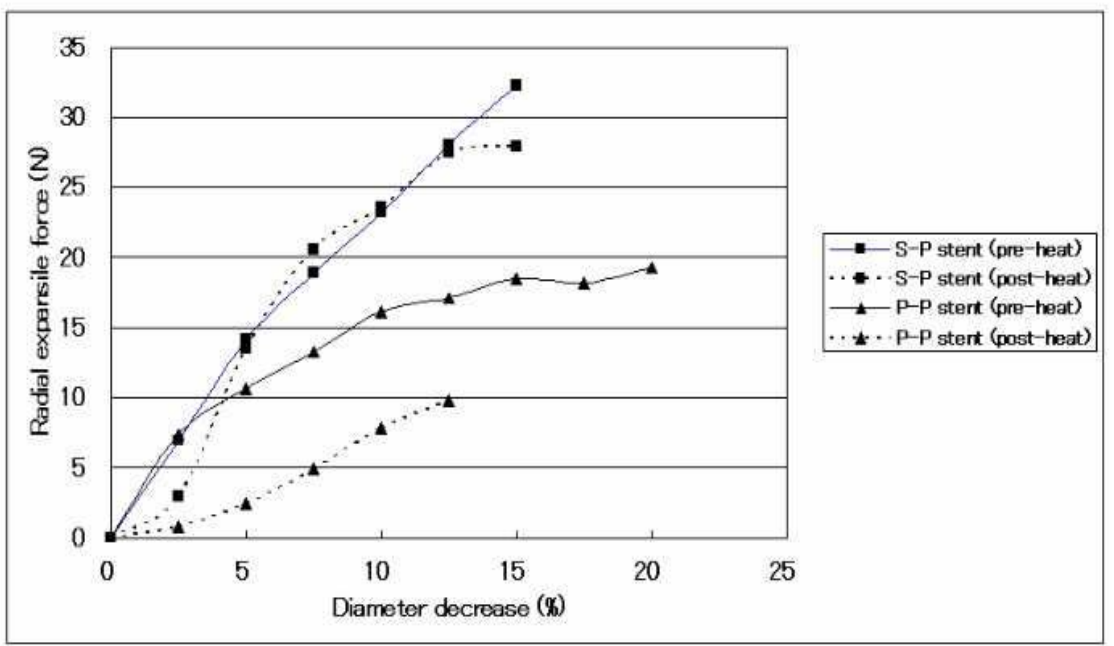

Fig. 4. Radial expansile force responseof the heat processed stents; The radial force decrease of the S-P stent was within 5 percent of the original force. PLA stent did not exhibit effective radial force after the process

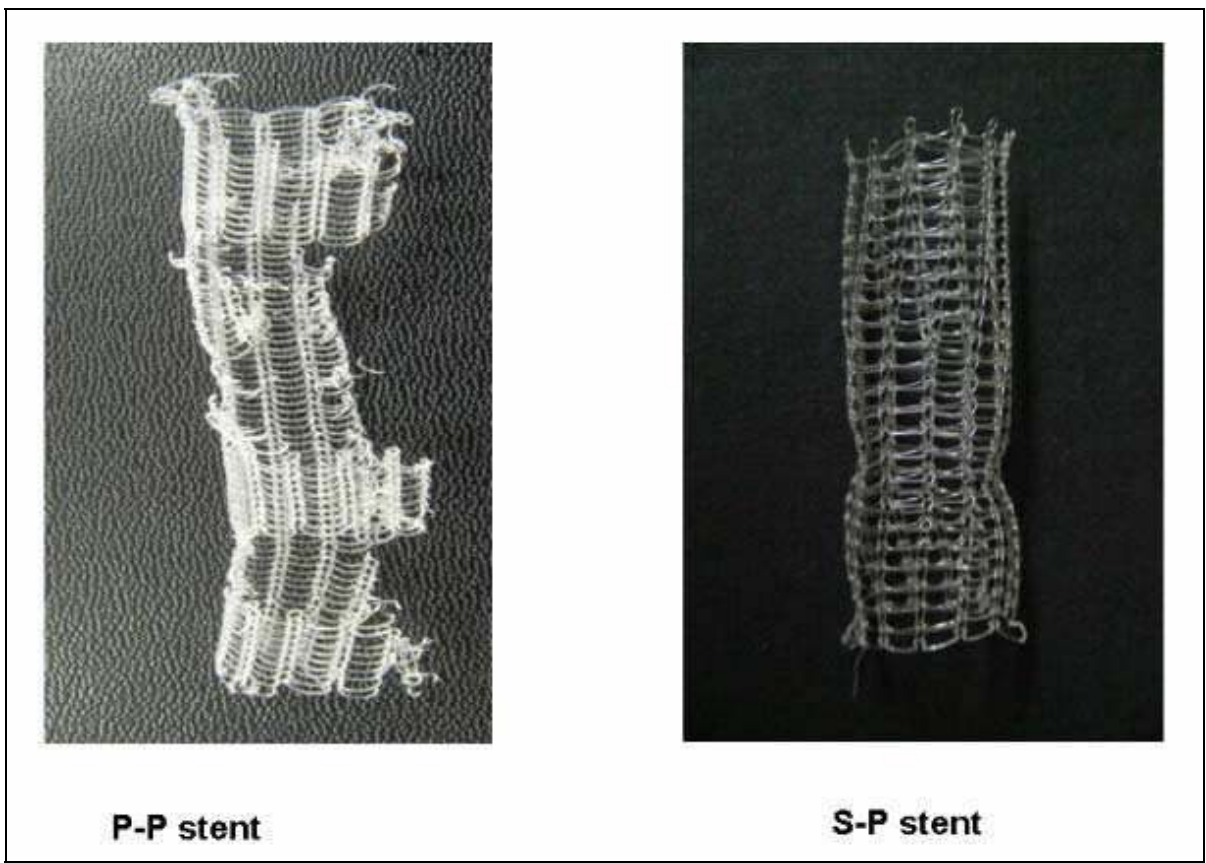

Fig. 5. Gross appearance of the heat processed test stents; The S-P stent maintained its original shape, even after PLA degradation, but the P-P stent was destroyed with slight compression 


\subsubsection{Retrievability of metallic core component}

After the heat process, the non-cross-linked metal core of the S-P stent was easily straightened by pulling the end of the stent wire. There was slight displacement of the stent in the silicone tube while pulling the wire, but no unusual resistance, deformity or torsion of the core was observed. As a result, the residual metal core component was removed from the silicone tube without difficulty (Fig. 6).

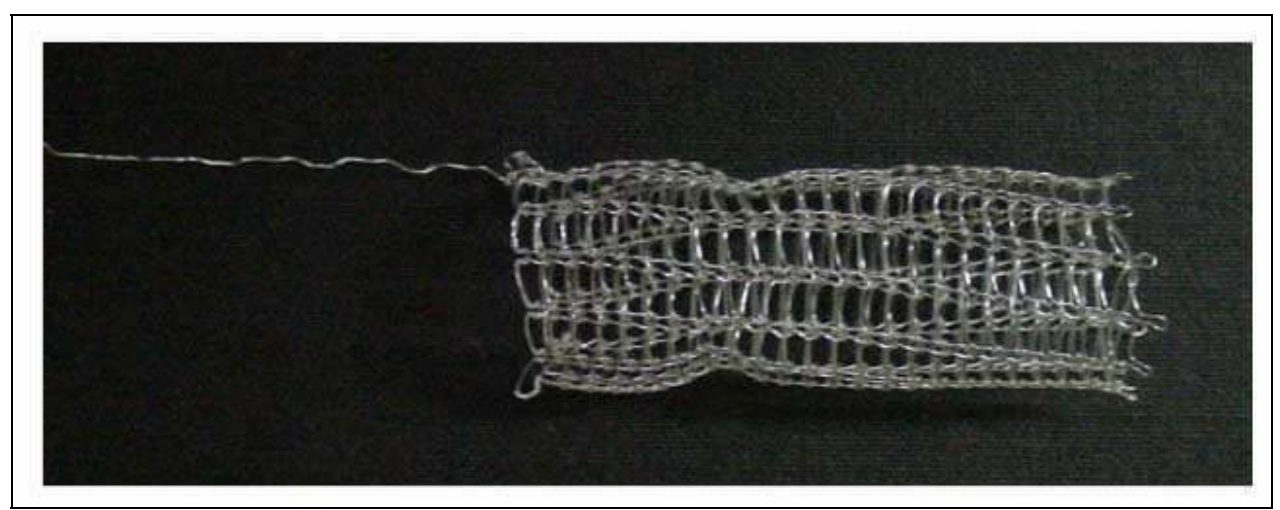

Fig. 6. Unlocking performance of metal component of the heat processed S-P stent; The noncross-linked metal core was easily straightened by pulling the end of the stent wire, and was removed from a silicone tube without difficulty

\subsection{Discussion}

Silicone are characterized by high elasticity and retrievability, and are often used for temporary stenting, such as strictures of benign etiology (Schildge et al., 2001), or regions where flexibility is required due to various organ movement, such as the trachea (Puma et al. 2000). However, they also have disadvantages related to the complex stenting procedure and structural problems. Rigid fiberscopy under general anesthesia is required for stenting; the stent wall is too thick to create effective radial force, which often results in stent migration or displacement. Therefore, the clinical applications of silicone stents are limited when compared to metallic stents.

So-called bioabsorbable stents have been developed for temporary stenting purposes. They are designed to degrade in the body at certain periods of time after deployment (Korpala et al., 1999). A common bioabsorbable material for this purpose is poly-l-lactic acid (PLLA), which has been widely used as a surgical suture material, and its biocompatibility and degradability in the human body has been established (Isotalo et al., 2002; Zilberman et al. 2005). However, the physical properties of PLLA fibers, such as tensile strength and elasticity, are inferior to metallic wires (Grabow et al., 2005); therefore, the potential uses of this material in stents are limited.

Under these circumstances, the purpose of our study was to improve the retrievability of metallic knitted stents, and for this purpose, we produced a composite material stent comprising bioabsorbable fiber and metallic wire. Combination of dissimilar materials with different physical properties in stent design has been in practice in the dynamic stent (Freitag et al., 1994), for which a silicone plate and elastic rubber were successfully combined to achieve excellent conformability with tracheal wall movement. Our composite 
material stent is another attempt for metallic knitted stent to use different materials in order to improve its retrievability.

Mechanical strength of the composite material stent is dependent on the metallic spiral component, and the bioabsorbable fiber component acted as a spacer by which the metallic core can be properly introduced, positioned and fixed at the target site. Therefore, apparent reduction of radial expansile force was not observed between before and after artificial PLA degradation process. Fuerthermore, the fact that mechanical strength of the composite material stent, as a whole, is influenced by that of the metallic spiral core component means that stent mechanical characteristics can be designed simply by dimensional factors of a metallic wire, such as diameter, circumferential loop density, and length of a loop leg as well as physical properties of the material used. Without taking the effect of cross-linkage of stiff metallic wire with itself into account, stent structural parameters can be optimized.

The changes made to the composite material stent structure may have additional benefit to its characteristics; excellent kink resistance and low axial resilient force. Upon our observation of why stent kinking occurs in conventional metallic knitted stents, it is brought about by the collision of adjacent metallic loops during bending of the stent, resulting in compressed loops protruding inward. In contrast, because the metallic loop is surrounded by soft loops of non-metal fibers in the hybrid stent, collision between metallic loops is not likely to occur, and therefore kinking may be avoided. Furthermore non-cross-linked metallic loop structures produce only resilient torsial force at stent bending, and thus the straightening force of the stent is minimized and excellent conformability may be achieved.

Our study was limited by the fact that PLA degradation process was not evaluated in vivo. The bioabsorbable fiber component is expected to act as a spacer by which the metallic core can be properly introduced, positioned and fixed at the target site, and to be degraded after metallic core has been fixed. However, once placed in the body, it is not possible to control reaction speed of PLA hydrolyzation reaction. Loco-regional settings of the target site, such as existence of bacteria, influence the reaction, which may result in insufficient fixation of the metallic core due to unexpectedly early PLA degradation, or in disturbance in stent removal due to persistence of unhydrolyzated PLA fiber. Thus, further experimental studies in vivo are warranted.

In conclusion, the composite material stent comprising metallic wire and bioabsorbable fiber can preserve effective physical properties comparable with the identical metallic stent. And it also has high retrievability after bioabsorbable fiber degradation.

\section{Composite material stent comprising $\mathrm{Ni}$-Ti wire and PBO fiber, and its mechanical characteristics}

\subsection{Background}

An ideal stent has not only expansile force to enlarge a stenotic lumen but also elasticity to follow flexibly various forms of external force such as bending and compression caused by movement of the body (Fransen et al., 2003).

A stent's characteristics such as the mechanical strength and transformation due to loading are determined by the physical properties of the materials and by the design of the mesh pattern (Flueckiger et al., 1994). As for the metallic stent, it shows strong elasticity against external force such as bending and compression with its strong expansile force.

Caution is required when implanting a metallic stent in a curved luminal organ because it may cause ulceration or perforation in tissues by giving excess surface pressure as it unwinds to the linear form. 
With a view to developing a stent with sufficient expansile force against stenosis while following flexibly bends in luminal organs, stents knit in tiers were created using wires of different degrees of bending stiffness. The results showed that expansile force and flexibility can be gained simultaneously by an appropriate combination of materials and textile design. The purpose of this experiment was to evaluate the physical properties of a composite material stent comprising metallic wire and polymeric fiber.

\subsection{Materials and methods}

\subsubsection{Stent structure}

For the metallic wire, nickel titanium alloy (Ni-Ti) wire, $0.12 \mathrm{~mm}$ in diameter, was chosen. For the non-metallic wire, multifilament fiber (ZYRON®-AS; TOYOBO, Osaka, Japan) consisting of poly-phenylene-benzobisoxazole (PBO), $0.18 \mathrm{~mm}$ in diameter, was selected. These materials were knit at the ratio of 1 to 1 into a cylinder having the same textile pattern as the Ultra Flex Stent (Fig. 7). The size of the stent was $15 \mathrm{~mm}$ or $8 \mathrm{~mm}$ in diameter and $80 \mathrm{~mm}$ in length (N-Z stent). For control, a metallic stent was created using Ni-Ti only but having the same textile pattern (N-N stent). After the stents were knit, they were heated for thirty minutes at 400 degrees Celsius, for a shape memory treatment of the $\mathrm{Ni}-\mathrm{Ti}$ alloy. The loop pitches of the Ni-Ti wires after the shape memory treatment measured $1.84 \mathrm{~mm}$ in the $\mathrm{N}-\mathrm{Z}$ stent and $1.92 \mathrm{~mm}$ in the N-N stent. Also, for comparison, three stents of $8 \mathrm{~mm}$ in diameter that are already in clinical use were prepared: a Wall stent (Boston Scientific Co., Natick, USA), a Spiral Z stent (Medico's Hirata, Tokyo, Japan), and a SENDAI stent (Piolax Medical Device Co., Yokohama, Japan).

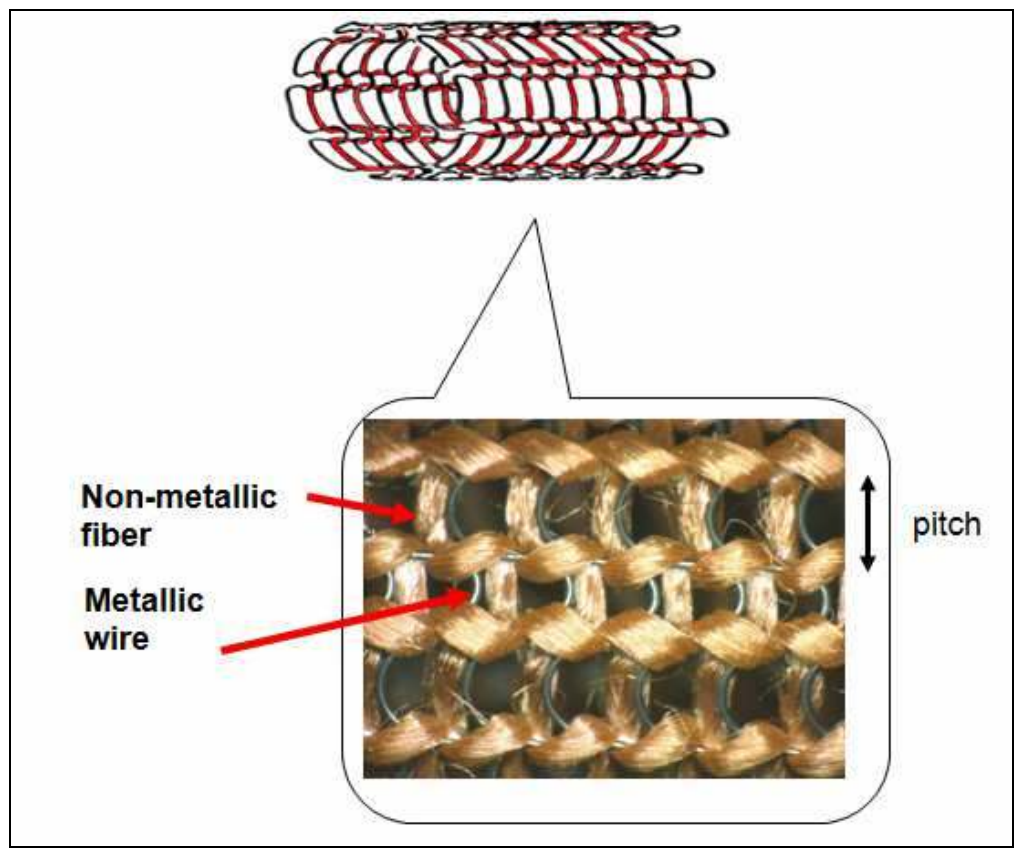

Fig. 7. A composite material stent comprising Ni-Ti wire and $\mathrm{PBO}$ multifilament fiber. The photo was taken prior to the shape memory heat treatment of the Ni-Ti 


\subsubsection{Evaluation of mechanical properties}

1. Radial expansile force

An N-Z stent and an N-N stent of $15 \mathrm{~mm}$ in diameter were chosen as the objects of study. One metallic plate was attached to the top of a universal testing machine (RTC-1350A, ORIENTEC Co., Ltd., Tokyo, Japan) and another to the bottom. The stents were set between the plates. The initial point of measurement was determined when the upper metallic plate was lowered to a point where the diameter of the stent was $6 \mathrm{~mm}(40 \%$ of the original). The pressure was released by raising the upper metallic plate at $5 \mathrm{~mm} / \mathrm{min}$. The autograph connected to the upper plate measured the restoring force of the stent sequentially to the ratio of the amount of transformation of the stent. When the value of the force reached zero, the upper plate was lowered at $5 \mathrm{~mm} / \mathrm{min}$ to the initial point. This process was also measured. A cycle was defined by this up-and-down, and the radial expansile force was calculated on the basis the average score after two cycles (Fig. 8).

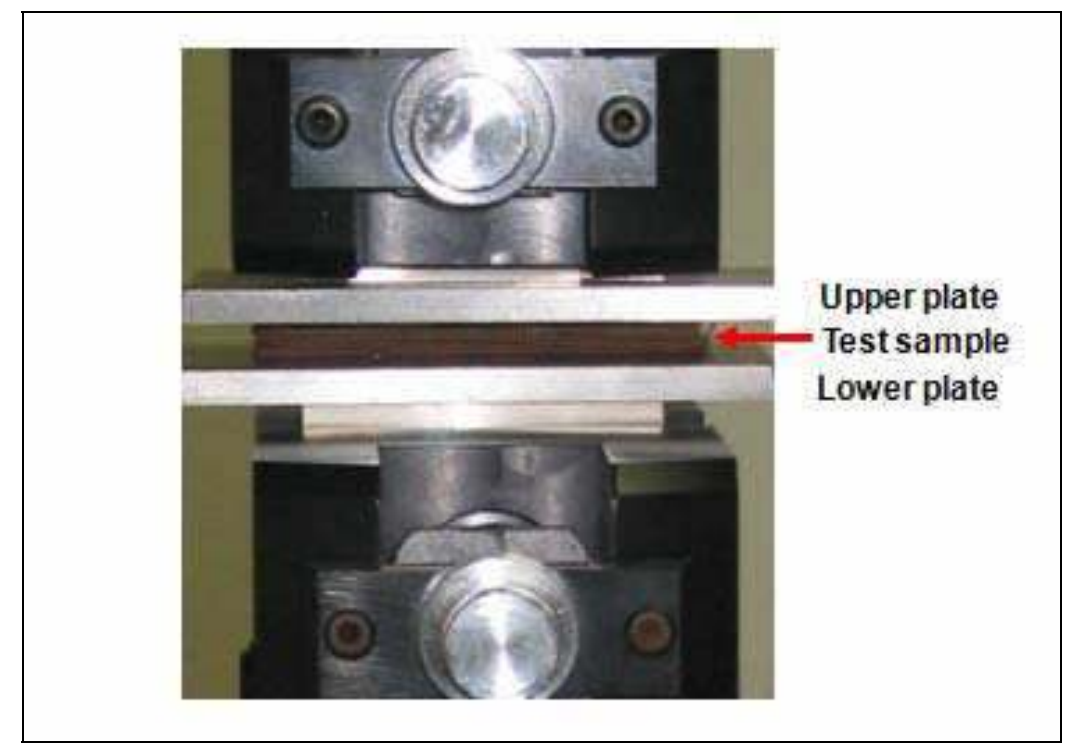

Fig. 8. A method of measuring radial expansile force. The restoring force of the stent on the upper plate when the stent was given a compressive weight was measured as the stent's radial expansile force.

\section{Bending force}

An N-Z stent and an N-N stent of $8 \mathrm{~mm}$ in diameter, a Spiral Z stent, a SENDAI stent, and a Wall stent were chosen as the objects. A mandrel was inserted $4 \mathrm{~cm}$ deep at one end of each stent so the stents were fixed on one side. The free ends of the stents were contacted by a push-pull gauge (IMADA Co., Aichi, Japan) in the direction of the diameter. External force was given to the stents through the gauge until they were bent to an angle of 90 degrees. With the stents bent at an angle of 90 degrees, the weight of the load was measured on the push-pull gauge. The bending force was calculated on the basis of the average values after three measurements (Fig. 9). 


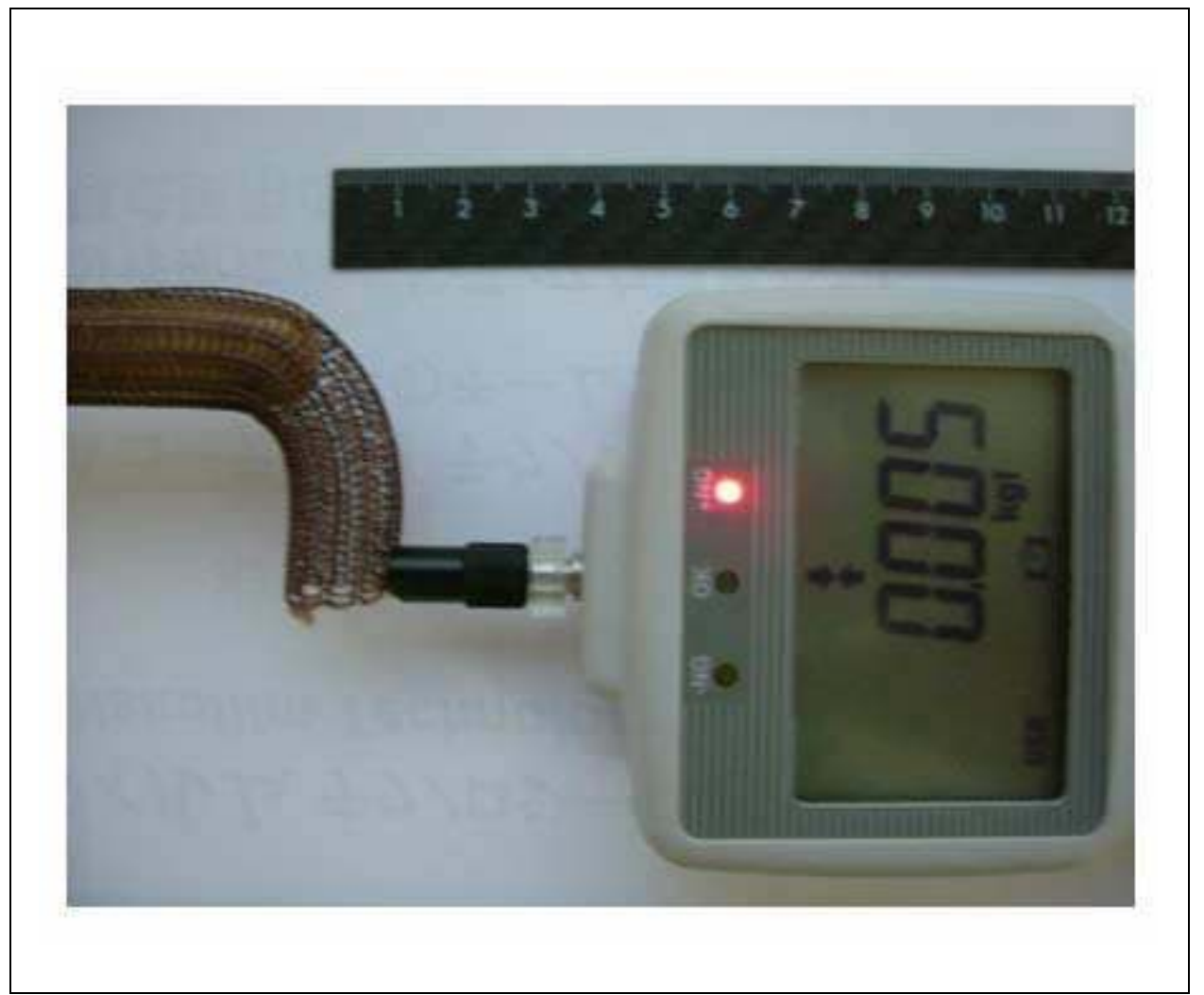

Fig. 9. With a mandrel inserted at one end of each stent, the other end was contacted by a push-pull gauge (IMADA Co., Aichi, Japan) on the surface of the stent, and was given external force until the stents were bent to an angle of 90 degrees. The value of the weight on the gauge was defined and measured as the bending force of the stent

3. Kink resistance

The objects were an N-Z stent, an N-N stent, a Wall stent, and a Spiral Z stent. A mandrel was inserted $20 \mathrm{~mm}$ deep at either end of each stent. The stents were bent manually via the mandrels on a mat measuring angles. The bending angles were measured on the basis of the angles the two mandrels made, and the outer diameters of the most stenosed part of the kinks were measured. The bending angles of the stents were measured at an angle of 0 through 180 degrees with an interval of 10 degrees.

\subsection{Results}

1. Radial compressive force

For the N-Z and the N-N stents, the radial expansile forces increased in a virtually linear manner when they were loaded and compressed to $40 \%$ of the original diameter $(9 \mathrm{~mm}$ compression). At this point, the radial expansile force measured $6.1 \mathrm{~N}$ in the $\mathrm{N}-\mathrm{Z}$ stent and 
$5.0 \mathrm{~N}$ in the N-N stent (Fig. 10). In other words, compared with the metallic stent of the equivalent mesh density, the hybrid stent showed greater expansile force.

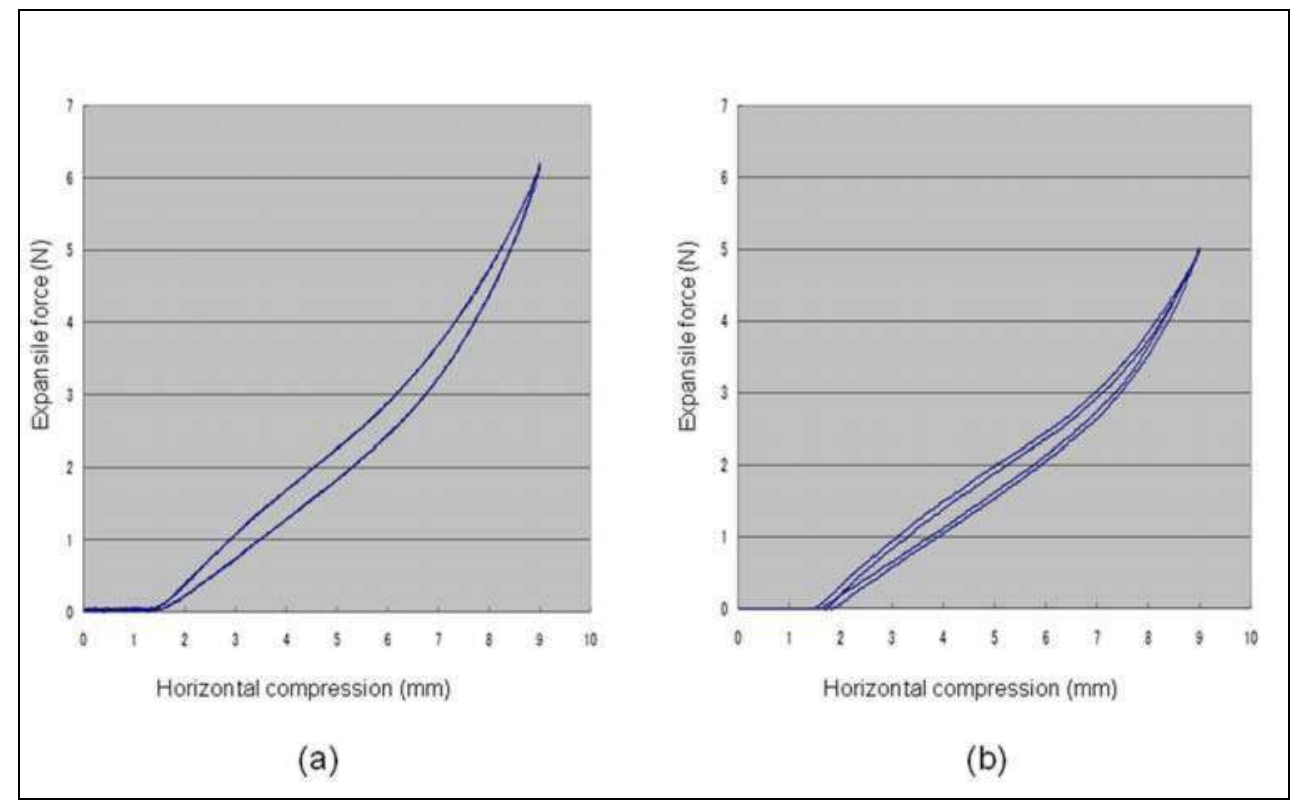

Fig. 10. The relation of the amount of horizontal compression to expansile force in the $\mathrm{N}-\mathrm{Z}$ stent (a) and N-N stent (b). In the range of $9 \mathrm{~mm}$ compression $(40 \%$ of the original diameter), the expansile force increased in proportion to the amount of compression for both stents

\section{Bending force}

When the stents were bent at the angle of 90 degrees, the bending force measured $0.003 \mathrm{~N}$ in the $\mathrm{N}-\mathrm{Z}$ stent, $0.034 \mathrm{~N}$ in the N-N stent, $0.09 \mathrm{~N}$ in the Spiral Z stent, $0.11 \mathrm{~N}$ in the SENDAI stent and $0.03 \mathrm{~N}$ in the Wall stent.

3. Kink resistance

Kinks emerged at an angle of about 60 degrees in both the N-N and the SENDAI stents. As the bending angle increased the kinks showed further development until the lumen was stenosed almost completely at an angle of 150 degrees or more. A slight kink was formed at a bending angle of 150 degrees or more in the N-Z stent, while the kink remained small even when the stent was bent further. In the Spiral $\mathrm{Z}$ stent, the largest kink was observed at an angle of 120 degrees. The Wall stent didn't have any kinks on the central part at a bending angle of 100 degrees or more. Rather it showed a slight increase in the diameter (Fig. 11). When they were bent to an angle of 180 degrees, the lumens of the N-N, the SENDAI and the Spiral Z stents were stenosed almost completely, while the kink on the N-Z stent was not significant (Fig. 12). 


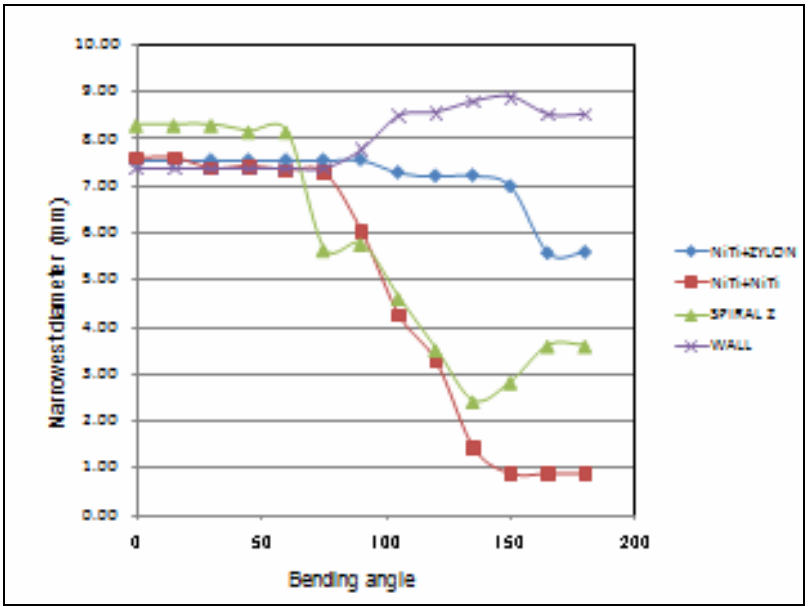

Fig. 11. The relation of the bending angle of the stent to the narrowest diameter of kinks. For spiral Z stent and N-N stent, kinks emerged at an angle of about 60 degrees, abd grew larger as the bending angle increased. On the N-Z stent, however, no apparent kinks emerged until the stent was bent to an angle of 150 degrees. No kinks emerged that would cause stenosis of the lumen as the stent was bent further

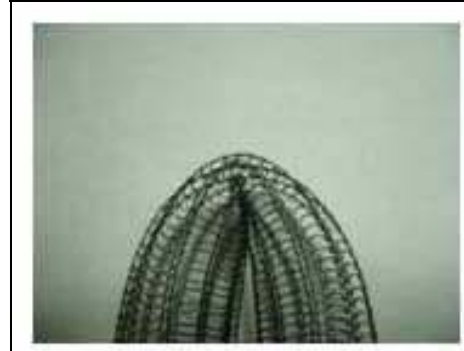

(a)

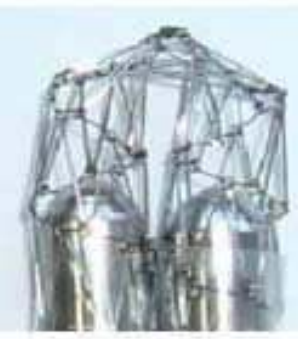

(c)

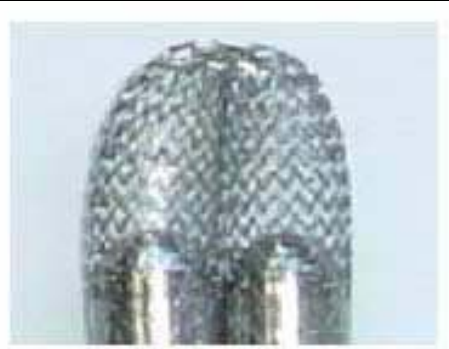

(b)

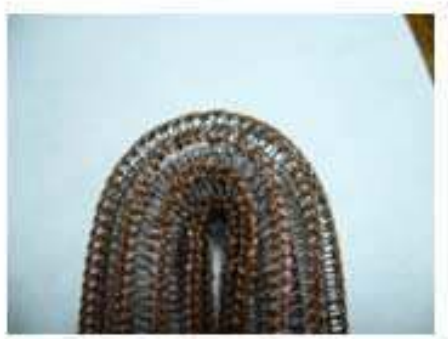

(d)

Fig. 12. Occurrence of kinks on bending to an angle of 180 degrees. In the N-N (a), the SENDAI (b), and the Spiral Z stents (c), the lumen was completely stenosed, while the kink was minor in the $\mathrm{N}-\mathrm{Z}$ stent $(\mathrm{d})$ 


\subsection{Discussion}

Metallic stents can be classified according to their structure into the following types: ones made with a metallic wire knit into a cylinder (e.g., the UltraFlex stent), ones using two or more metallic wires forming a braid (e.g., the Wall stent), hollow tubes molded with a laser beam (e.g., the Cyphor stent) and others. In knitted stents, the loops of the mesh form the hollow cylindrical structure. In the case of stents molded with laser, a regular array of closed and semi-closed polygonal structural units called cells play the role of the loops. The adjacent loops of knitted stents are fixed by confounding, whereas the cells in laser molded stents are connected with linking components. It is one of the necessary conditions for loops or cells to maintain a rigid array if a stent is to yield effective expansile force. At the same time, however, it will also be a cause of restoring force against bending transformation. It is difficult to design a stent of this type that has low restoring force while retaining strong expansile force.

In contrast, if stents receive a strong bending transformation, adjacent loops or cells may come into contact at unexpected parts. Or they may yield an irregular external force through the joints. These may result in transformation and deviation of loops and cells, with part of them protruding inside the lumen of the stents.

In their discussion on the mechanism of emergence of kinks in stents using the Finite Element Method, Mori et al. state that stent meshes or struts contacting or colliding with each other will cause decrease in their flexibility and lead to formation of kinks (Mori et al., 2004).

As a solution to interference of adjacent loops in knitted stents in bending transformation described above, we devised knitted stents whose two wires differed significantly in bending stiffness. Each of the wire intersected regularly at the small loops, forming a structure of two spirals of different materials knit together.

This structure reacts differently to external force from the same structure consisting of one single metal. In bending transformation, the fiber loops, coupled with the metal loops, transform themselves, keeping the transformation of the metal spiral loops to a minimum. This yields little elasticity caused by the restoring force in bending transformation of the metallic spiral component, making the restoring force related to the twisting stiffness of the metallic material the only cause of the restoring force. Also, kinks are less likely to occur as the metallic loops do not come into contact with each other. As for the load in the direction of the diameter, materials with low stiffness function as a spacer to maintain the spiral structure of the material of high stiffness enabling to produce effective radial expansile force. Our approach also prevents the metallic spiral structure from significant transformation or divergence by weight.

It is in this point that our approach differs from loose spiral structures. This is the reason why the composite material stents yield effective expansile force. The expansile force can be adjusted by the bending stiffness of the material of high bending stiffness and the pitch and height of the loops. The stents developed for this experiment had a knitted structure generally in use such as in the Strecker and the Ultraflex stents. However, our hybrid materials approach has made it possible to adjust expansile force, anti-kink characteristics, and axial restoring force independently, which was not possible in metallic or laser molded stents.

In conclusion, a composite material knitted stent, compared with a metallic stent of the same pattern, allows strong radial compressive force while keeping bending force low. This hybrid approach is also superior in the anti-kink characteristics to one using a single metallic material. 


\section{Future research}

In this experiment we demonstrated that the properties of a composite material knitted stent using metallic and non-metallic materials can be manipulated easily. As we have shown, a composite material stent comprising metallic and a bio-absorbing textile can offer advanced removability from the body without losing the structural properties of the stent. It can also be used as a drug eluting stent by filling the bio-absorbing textile with therapeutic medicine such as an anticancer drug.

Most of the drug eluting stents currently in use release therapeutic medicine from polymers covering the surface of a metallic stent. Our hybrid materials stents can contain multiple agents by selecting an appropriate textile.

The combination of a metal and a fiber can also change the structural properties of a stent. Realizing strong expansile force and flexibility at a high level was hard in metallic stents. In the combination of $\mathrm{PBO}$ fiber and $\mathrm{Ni}$-Ti wire, our stents realized a stronger expansile force and a greater conformity against bending than metallic stents of the same textile pattern. They also achieved a superior anti-kink characteristics.

The concept of employing multiple materials in a stent is not limited to the knitted stent structure we used in this experiment, but it can be applied to other stent structures as well. Existing stents such as the Spiral $\mathrm{Z}$ and the Wall stents can be expected to show improvement in removability and be designed to contain therapeutic medicine by employing multiple materials (Fig. 13).

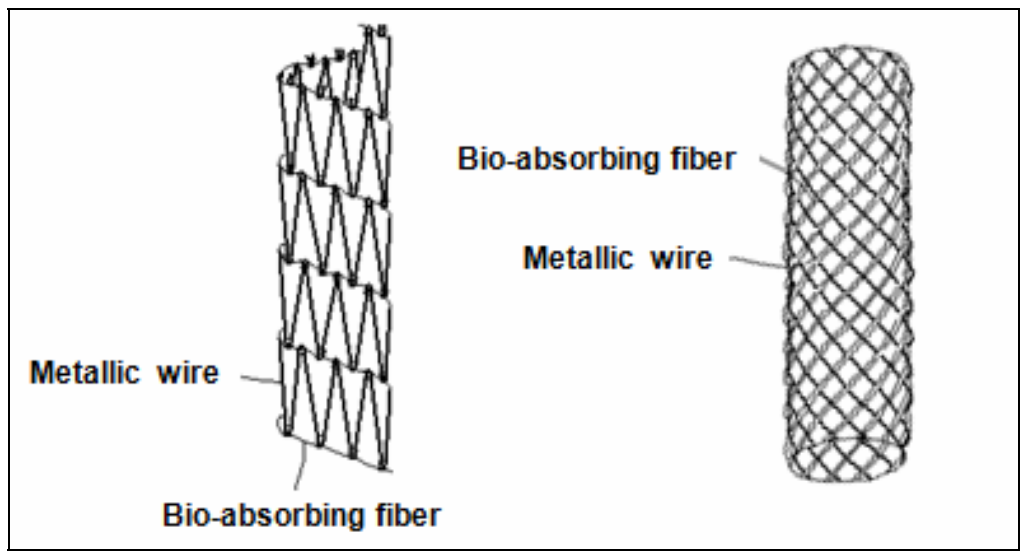

Fig. 13. An example of hybridizing existing stents. In a Spiral Z stent (a) using a bioabsorbing fiber as the linking material, the Z-shaped loops will show improved removability from the body. In the Wall stent (b), bio-absorbing fiber can be woven between the wires. By filling the textile with therapeutic medicine, the medicine can be released as the textile dissolves

\section{References}

Flueckiger F, Sternthal H, Klein GE, Aschauer M, Szolar D, Kleinhappl G. (1994). Strength, elasticity, and plasticity of expandable metal stents: in vitro studies with three types of stress. J Vasc Interv Radiol, 5, 745-750. 
Fransen GA, Desgranges P, Laheij RJ, Harris PL, Becquemin JP. (2003). Frequency, predictive factors, and consequences of stent-graft kink following endovascular AAA repair. J Endovasc Ther, 10, 913-918.

Freitag L, Eicker R, Reuter S. Theoretical and experimental basis for the development of a dynamic airway stent. (1994). Eur Respir J, 7, 2038-2045

Grabow N, Schlun M, Sternberg K. (2005). Mechanical properties of laser cut poly(L-lactide) micro-specimens: implications for stent design, manufacture, and sterilization. $J$ Biomed Eng, Feb 127(1), 25

Isotalo T, Talja M, Valimaa T. (2002). A bioabsorbable self-expandable, self-reinforced polyL-lactic acid urethral stent for recurrent urethral strictures: long-term results. $J$ Endourol, Dec, 759-62

Korpala A, Aarnio P, Sariola H. (1999). Bioabsorbable self-reinforced poly-L-lactide, metallic, and silicone stents in the management of experimental tracheal stenosis. Chest, 115(2), 490-495

Miura S, Yoshioka T, Furuichi K, Tanaka T, Kichikawa K, Ohishi H. (2003). Mechanical Properties of Biliary Metllic Stents: An Experimental Comparison. NIPPON ACTA RADIOLOGICA, 63, 201-209

Mori K, Saito T. (2004). Effects of stent structure on stent flexibility measurements. Ann Biomed Eng, 63, 733-742.

Noppen M, Stratakos G, D'Haese J, Meysman M, Vinken W. (2005). Removal of Covered Self-Expandable Metallic Airway Stents in Benign Disorders: Indications, Technique, and Outcomes. Chest, 127:482-487

Puma F, Farabi R, Urbani M. (2000). Long-term safety and tolerance of silicone and selfexpandable airway stents: an experimental study. Ann Thorac Surg , 69, 1030-1034

Schildge J, Hauk H. Successful treatment of benign tracheal stenosis with a silicone stent (Polyflex-Stent) over 5years. (2001). Pneumologie, 55, 152-158

Song HY, Shim TS, Kang SG. Tracheobronchial strictures: treatment with a polyurethanecovered retrievable expandable nitinol stent-initial experience. (1999). Radiology, 213, 905-912

Zilberman M, Nelson KD, Eberhart RC. Mechanical properties and in vitro degradation of bioabsorbable fibers and expandable fiber-based stents. (2005). J Biomed Mater Res B Appl Biomater, 74(2), 792-9 


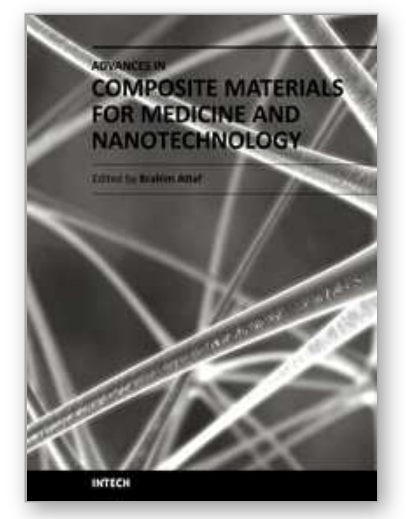

\author{
Advances in Composite Materials for Medicine and \\ Nanotechnology
}

Edited by Dr. Brahim Attaf

ISBN 978-953-307-235-7

Hard cover, 648 pages

Publisher InTech

Published online 01, April, 2011

Published in print edition April, 2011

Due to their good mechanical characteristics in terms of stiffness and strength coupled with mass-saving advantage and other attractive physico-chemical properties, composite materials are successfully used in medicine and nanotechnology fields. To this end, the chapters composing the book have been divided into the following sections: medicine, dental and pharmaceutical applications; nanocomposites for energy efficiency; characterization and fabrication, all of which provide an invaluable overview of this fascinating subject area. The book presents, in addition, some studies carried out in orthopedic and stomatological applications and others aiming to design and produce new devices using the latest advances in nanotechnology. This wide variety of theoretical, numerical and experimental results can help specialists involved in these disciplines to enhance competitiveness and innovation.

\title{
How to reference
}

In order to correctly reference this scholarly work, feel free to copy and paste the following:

Yuzo Shomura, MD. (2011). Composite Material Stent Comprising Metallic and Non-metallic Materials, Advances in Composite Materials for Medicine and Nanotechnology, Dr. Brahim Attaf (Ed.), ISBN: 978-953307-235-7, InTech, Available from: http://www.intechopen.com/books/advances-in-composite-materials-formedicine-and-nanotechnology/composite-material-stent-comprising-metallic-and-non-metallic-materials

\section{INTECH}

open science | open minds

\author{
InTech Europe \\ University Campus STeP Ri \\ Slavka Krautzeka 83/A \\ 51000 Rijeka, Croatia \\ Phone: +385 (51) 770447 \\ Fax: +385 (51) 686166 \\ www.intechopen.com
}

\author{
InTech China \\ Unit 405, Office Block, Hotel Equatorial Shanghai \\ No.65, Yan An Road (West), Shanghai, 200040, China \\ 中国上海市延安西路65号上海国际贵都大饭店办公楼 405 单元 \\ Phone: +86-21-62489820 \\ Fax: +86-21-62489821
}


(C) 2011 The Author(s). Licensee IntechOpen. This chapter is distributed under the terms of the Creative Commons Attribution-NonCommercialShareAlike-3.0 License, which permits use, distribution and reproduction for non-commercial purposes, provided the original is properly cited and derivative works building on this content are distributed under the same license. 